\title{
9. Accommodating agency and contingency: towards an extended strategy for engagement
}

\author{
Frances Morphy, Will Sanders and John Taylor
}

The National Census is a broad-brush instrument with two major objectives: to provide an accurate count of the national population and to collect data on demographic and socioeconomic characteristics that are comparable across different sectors of the population, variously defined. The Indigenous Enumeration Strategy (IES) has evolved through the years in response to the perceived 'difference' of the Aboriginal and Torres Strait Islander populations of Australia. In the 2006 Census, we were in a unique position to observe the workings of the IES, from the design of the collection instrument through to the processing of the data collected in the field. Our findings suggest that the IES has probably reached a point in its development where the injection of ever-increasing resources into essentially the same generic set and structure of activities could begin to produce diminishing returns to output (data quality) unless there is some fundamental reworking of the way in which the strategy is delivered. In particular, we suggest that the manner in which the Australian Bureau of Statistics (ABS) engages with local communities and their organisations needs to change.

We begin with a short discussion of the Interviewer Household Form (IHF) before turning to what emerged as the major theme of our 2006 research: the difficulties of using a dwelling-based count that assumes a sedentary lifestyle to capture a highly mobile population - a population that manifests little consciousness of or interest in the purposes of the census. We will frame this discussion in terms of agency - the agency of Indigenous people and the organisations that sit on the interface between local Indigenous populations and the state-and contingency - the need to accept the contingent factors that influence Indigenous mobility and to build a response to contingency more explicitly into the collection strategy. We argue that to contain the effects of contingency it is necessary for the ABS to make much more productive use of local knowledge at the regional and the local level. In part, this entails building the agency of local institutions into the process much more effectively.

\section{The Interviewer Household Form: from data collection to data coding}

As indicated in Chapter 1, evaluation of the IHF was initially a primary objective of the research since the IHF- as a single matrix form-was considerably 
different from the two-form collection instrument of 2001. In all four case-study accounts (Chapters 3-6), there is a sense that the new IHF (see Appendix A) worked quite well. The most obvious of the remaining structural problems is the ordering of the questions on persons temporarily absent (PTA) before the questions about who was at the dwelling - residents and visitors - at the time of the count. We discuss this issue - which could have had a substantial effect on the adequacy of the count - in Appendix B. All four case studies also contain comments about questions that did not work very well for various reasons. These too are discussed in detail in Appendix B.

After the census count, the observation of the final checking of census forms at the Darwin Census Management Unit (CMU) and the conversion of paper-based returns to computer-read unit record data at the Data Processing Centre (DPC) in Melbourne allowed us to follow raw data all the way from collection to processing. This has provided a unique basis for evaluating census output. Questions such as how household structures are compiled, how occupations are determined and what contributes to final head counts have never before been analysed in this way. While we note the intense, often highly technical, scrutiny of census returns that uses a mix of formulaic criteria and almost forensic guile, at the end of the day there remains an inevitable sense of human agency in decision-making about certain data categorisations, not least because the overarching framework for this in terms of the ultimate purpose of data collection remains, inevitably, a function of state administration.

Observation of the family-coding procedures (Chapter 8) confirmed our findings in 2001 (Morphy 2002, 2004, 2006; see also Morphy 2007) that the census cannot capture fully the complex family structures of Indigenous households and in many ways it is better if it does not try to do so. We conclude that the 2006 questions about relationships within households (Questions 13, 30 and 31) worked better than the 2001 questions, but they could still be improved somewhat (see Appendix B). We argue again also for the recognition of a new coding category of 'extended-family household'.

In the case of occupation coding, the current checklist for the majority of employed Indigenous people in remote Australia working on a Community Development Employment Projects (CDEP) does not adequately identify all economic activity. A significant proportion of the remote-area Indigenous economy therefore remains invisible in the 2006 Census.

These observations on coding point to the very partial way in which the census captures Indigenous social and economic life in remote Australia. We return to this question in a postscript to this chapter. 


\section{Common themes}

In this section, we focus on common themes that emerged from the four case studies in the field. These observations of the process in 2006 lead to a critique of the structure and processes of the IES and to suggestions for its improvement in 2011. One general initial point to be made - which arises out of the multi-sited nature of the census - is the need for constant monitoring of the flow of information to and from the central administration of the ABS, the regional offices, the Census Field Officers (CFOs) and the field staff, and the need for knowledge and local insights to be kept available locally for the next census exercise and not just fed back to the centre. Where vital links in the information chain failed - as occurred in some instances in regard to the proper placing of PTA on census forms, or in non-response to the Indigenous status question - this had major repercussions down the line, with complications emerging in the determination of final classifications at the DPC. One suggestion for resolving some of the translation issues involved in moving from field encounters to the production of statistical information would be to swap the roles of former DPC and CMU staff - at least in the training of each - so as to bring the different skills, experiences and insights to bear at each end of the process.

\section{The role of the Census Field Officer}

In all the case-study areas, with the possible exception of the Alice Springs town camps, the case studies show that the role of the CFO, as presently conceived, is inherently impossible. Various factors contribute to this situation. The size of the areas for which the CFOs are responsible and the logistical difficulties arising from the remoteness of many discrete Indigenous communities from the main concentrations of population - and hence from administrative centres - is an intractable problem. The difficulties the CFOs experienced in three of the case-study areas in recruiting and retaining sufficient numbers of Community Coordinators (CCs) and collector-interviewers (CIs) threatened at times to undermine the whole exercise. In the way that the count is currently organised, the CFO cannot maintain control of the process across the entire region.

The training of the CFOs did not prepare them adequately for the realities of their task. Observation of this training (reported in Chapter 2) revealed two standout issues.

The combination of conducting the Community Housing and Infrastructure Needs Survey (CHINS), compiling the Discrete Indigenous Communities Database (DICD) and promoting upcoming census activities as a preliminary to census training proved a useful device for acquainting newly recruited CFOs with their field areas of responsibility, but the compression of these multiple tasks - especially the CHINS and the compilation of the DICD - into a single 
short field exercise also served to dilute the efficacy of efforts spent on census preparation and promotion.

Not only were CFOs new to the field operations they were about to encounter, so were those training them. The result was an inability to inject much corporate memory into the training process and this resulted in limited preparation for the many practical issues that individuals would face. To be fair, not all contingencies of this sort could be anticipated, but the truth is that many of the nuances involved in conducting the census were perforce learnt on the job. Essentially, CFO training requires more focus on practicalities and less on process. Greater attention should be given to the content of census forms and this could be aided by more explanation of the concepts, ideas and intentions that underpin form design. For example, the question of PTAs was rightly worrying the CFOs during their training, but they received only limited conceptual or substantive guidance on how to deal with them.

The support offered to the CFOs in the field was limited by structural and technological factors. Lack of access to computerised records that would have informed them of the progress of the count in nearby regions made it impossible for them to check, in the field, whether people 'temporarily absent' from where they were said to be residents were likely to have been counted in the places to which they were said to have gone. Lack of computers in the field also made keeping and updating their own records of progress much more arduous than necessary. They had no email access to the CMU, and were forced to use often-unreliable satellite phone links to maintain contact with the CMU. In the Northern Territory the managers at the CMU were responsible for many other tasks besides overseeing the IES, and often could not respond as quickly as was desirable to queries from the field.

It is significant that the most successful count observed in 2006 was in the Alice Springs town camps, where there was a vast improvement between 2001 and 2006. This can be attributed to two factors: the redesigned IHF and better engagement between the ABS and Tangentyere Council, the organisation that services and represents the town camps. Even in Alice Springs, however, there were factors that prevented the $\mathrm{CFO}$ and Tangentyere from cooperating fully with each other. For example, Tangentyere had developed a list of town camp residents through its own research work in 2005, but despite some early ideas about how it might be used, it was not in the end used to assist the census collection process.

At Wadeye and its outstations, there were signs of cooperation early in 2006 between the ABS and the Thamarrurr Regional Council (TRC), but when a suggested workshop at Wadeye failed to eventuate, the TRC began to feel little ownership of the coming census. Thereafter, the 2006 Census at Wadeye was destined to become an encounter between the ABS and individual households, 
with only limited involvement from the TRC. In the Arnhem Land case study, the local organisations felt no ownership of the census. They were not involved proactively in assisting the $\mathrm{CFO}$, and little attempt was made to encourage proactive involvement. They were nevertheless willing to offer assistance of a limited kind when asked.

In Fitzroy Crossing, there were some boundary problems between the IES and the general census enumeration, which reflected Fitzroy Crossing's status as an open, roadside town in a pastoral area of the Kimberley with a complex mix of Indigenous and settler populations. It appears that there were no formal procedures in place to ensure that the CFO and the Area Supervisor were aware of each other's activities.

\section{The role of the Community Coordinators and collector-interviewers}

The recruitment and training processes for CCs and CIs were confounded by the contingencies of life in remote Indigenous communities. Acting as a $\mathrm{CC}$ or $\mathrm{CI}$ is a complex task. The individual, whose first language is not English in many cases, and who might not have highly developed literacy in English, must master the content of a long and complex form and the elaborate and unfamiliar administrative procedures (outlined in Chapter 1) involved in ensuring the consistency, accuracy and completeness of the count. The training was compressed because of the realistic perception that there was likely to be attrition in attendance if the training went for more than one day, but this compression, and the fact that the CFOs were not themselves trained as trainers, meant that the training delivered to the CCs and CIs was not very effective in many cases. We observed time pressures on the CFOs - the time it took to recruit people and ensure their attendance at training sessions, and the necessity because of this to deliver training to the CCs and CIs in a joint session rather than giving the CCs additional support and training. Time pressures too meant that very often the CFO could not provide sufficient backup and feedback to the CCs and CIs during the early days of the collection process because of the necessity to move on to another community to begin the process again.

As a result, administrative procedures often broke down in the face of the contingencies of everyday life. At Fitzroy Crossing, Master Dwelling Checklists (MDCs) and Interviewer Dwelling Checklists (IDCs) were used in an inverse administrative process for bringing together the paperwork after the enumeration, rather than as a planning tool before the enumeration. At Wadeye and in Arnhem Land, CCs and CIs did not follow the IDCs that they had been given, and arguably this was inevitable when the presence or absence of so many people was contingent on so many factors external to the census enumeration. 


\section{Logistics, mobility and the time-extended rolling count}

The census as it is currently constructed is essentially a dwelling-based count, which assumes some degree of sedentariness among the population being counted. Remote Indigenous populations, however, behave in 'radically uncontained' ways (Morphy 2007). In Chapter 3, it is shown how this led to major problems for census administration in Arnhem Land, as dwellings - and even whole settlements - were often found empty and people were to be found in all sorts of different places during the extended period of the count. Sometimes people were found away from their usual dwelling, but wanted to be counted and were in fact counted 'as if' they were back there. There was an interesting political aspect to this 'as if' counting, as well as some practical administrative issues. At other times, where someone at least was present at a dwelling, many people were counted as PTAs; however, the ability to judge whether these people would also be enumerated elsewhere was limited.

The account of the Wadeye and outstations enumeration also addresses the theme of the high mobility of the population being counted. In this case, the issue is not just constant mobility between Wadeye, the outstations and nearby Indigenous communities, but a high level of dry-season mobility into Darwin. Although many of the people who were in Darwin were enumerated in the town camps as visitors from Wadeye, many others were camping out. There was concern that these last people were not being counted in Wadeye as PTAs, and also might not be counted in Darwin; or that if they were counted in Darwin on the 'Special Short Form' used for people not associated with a dwelling that this did not identify their community of usual residence, and so they were lost to Wadeye's final de jure count of usual residents.

The account of the 2006 IES in Fitzroy Crossing provides a useful widening of focus across a State/Territory border into Western Australia. The ABS administration in Western Australia clearly envisaged itself as doing a more 'standard' Indigenous enumeration than in the Northern Territory. The intention was that training of CCs and CIs would be done some considerable time before enumeration and that the time extension of enumeration would be kept to a minimum. At least in Fitzroy Crossing, however, and the southern Kimberley, there was not really that much difference from the time-extended rolling count that had been planned for the Northern Territory. Once training was done, there was encouragement to get on with the count straight away in case it took a while. Indeed, the enumeration dragged out in the southern Kimberley in just the same way as in the Northern Territory case studies.

\section{Residents, visitors and 'persons temporarily absent'}

There are definitional factors at play in the difficulties encountered by the ABS in enumerating the highly mobile remote Indigenous population. There is the 
question of how people define 'resident' and 'visitor'; this binary categorisation relies on a settler Australian view of relationship to place that, as the case studies and the observations at the CMU show, is in tension with an Indigenous view that rests on a sense of 'belonging' to a particular place. Then there is the question of what to do about 'residents' who are absent at the time of the count, and how to decide whether or not they are likely to be counted elsewhere.

In the Alice Springs town camps, there was a big improvement on the situation in 2001. Then, many visitors who were present at census time were nonetheless not counted due to the attempt to apply a 'usual residents' or de jure basis for enumeration. In 2006, a de facto approach was adhered to, with the result that all of those present were counted, at least as far as could be ascertained. While the same conceptual approach was adopted at all other sites, some confusion was observed about whether to count certain individuals as 'present' and precisely who qualified as a PTA. The observations at the CMU after the count revealed that this confusion was widespread in the Northern Territory. This was partly a consequence of the instruction to interviewers to be flexible and include people who were away but might not be counted elsewhere - a judgment call that was difficult to make at times for interviewers and interviewees. A fundamental difficulty also arose due to the rolling nature of the enumeration over several weeks, as this lent itself to the possibility of individuals-even households - being overlooked altogether or being double (or even triple) counted.

The reasons for and the regional patterning of PTA phenomena in 2006 need to be analysed in detail — centrally and at the CMU level — so that adequate training on how to treat different kinds of cases can be delivered, to the CFOs initially and then on down the line. Training on this issue should have a scenario component, in which people are presented with a range of 'real-life' examples to decide on. This should happen at all levels of training. It is hoped that the detailed information contained in our observations will allow the ABS to devise a better articulated strategy for dealing with PTAs in 2011. Our research shows that while mobility is pervasive, it is not random, and it also points to other factors that might reduce the scale of the problem: shortening the time frame of the rolling count and making better use of local knowledge.

\section{Suggestions for a new manner of engagement}

There will always be problems in enumerating a mobile population in terms of a dwelling-based count. The situation can, however, be ameliorated in three ways: by making better use of local knowledge, by having more and better-trained temporary staff on the ground and by reducing the time during which the enumeration takes place. All of these suggestions point in one direction: to a better form of engagement between the ABS and local institutions 
and agencies that are repositories of local knowledge and employers of local people.

\section{The involvement of local organisations}

Among the CFOs, opinion was divided on the question of how to involve local organisations in the census process. Some felt that they should be involved much more directly in the organisation of the count, so that best use could be made of their local knowledge and of their resources. They saw a need to develop a skill set out in the communities that could be tapped into at census time. Others thought that organisations should be kept at arm's length because they had a conflict of interest: it was felt to be in their interests to maximise the census count in their area because this had resource implications. ${ }^{1}$ Given this division of opinion, it is helpful that the evidence from our observations is unequivocal: the single most important factor that can enhance the quality of delivery and outcome from the IES is greater and more sustained engagement with local organisations and their personnel. In the Northern Territory in the future, this sector will include the new regional authorities as well as local community organisations.

The IES is designed in part to take advantage of the local knowledge of CCs and CIs, but it is clear that in the current social dynamic that operates in most communities it is unrealistic to expect the CFOs to be able to find and recruit sufficient numbers of adequately qualified and strongly motivated local Indigenous field staff. A variety of factors are involved, including low levels of literacy and numeracy in remote communities, which reduces the size of the potential pool of workers. Nearly all other major problems with the count follow from this. With inadequate numbers of collectors, the process becomes unduly prolonged and the problem of ensuring an accurate count is compounded by the mobility of the population. Moreover, those collectors who are recruited are faced with very burdensome workloads and, not surprisingly, many of them lose motivation, particularly when the payment system is slow and unsatisfactory. Most recruits are people with many other social obligations and it is easy for those obligations to take precedence over working for the ABS, particularly if people have to work long hours for a prolonged period to complete their workload.

In 2006, it was also possible that the general political climate had alienated many of those people who might have acted as CCs and CIs - that is, those who were more literate and more aware of events in the world beyond the local. Such people are no longer persuaded that taking part in the census delivers benefits

1 The question of the count in CHINS is a different issue: here organisations might legitimately include a 'service' population rather than simply a resident population, since they need the resources to service all of their clients in a mobile population. 
to them and their communities. Moreover, there is no sense among the general remote Indigenous population - at least in the communities where we observed the count - that the census enumeration is anything other than yet another 'government' intervention in their lives, which serves no direct purpose as far as they can see. It is viewed as irrelevant to their concerns, so more immediate local events always take precedence over taking part in the census. The inability to recruit sufficient numbers of field staff was a widespread phenomenon, and blame cannot be laid at the door of individual CFOs. The problem lies with the general nature of the engagement between the ABS and local populations.

In 2006, the lack of CCs and CIs, combined with the size of the regions they had to cover, made the job of the CFOs and their assistants well nigh impossible. One of the solutions advocated at the CMU debriefing was, in effect, to throw more bodies into the fray by increasing the number of CFOs next time, and maybe even the number of non-Indigenous CCs and CIs. It was suggested that greater use might also be made in 2011 of the team of Indigenous Assistants from Darwin. Such a solution begins to negate the rationale behind the use of local Indigenous people in the IES, and denies the value of their local knowledge.

There is another way to approach the problem, and that is to increase the sense of ownership of the census process at the local level, not so much by attempting a mass education campaign, but by strategic long-term engagement with local Indigenous organisations and their Indigenous and non-Indigenous staff, and with the staff of the regional authorities in the Northern Territory-once established. Such a relationship could be of mutual benefit.

At the moment, there is not enough capacity to deal with the inevitable contingencies that arise from the unpredictability and the scale of short-term mobility of remote Indigenous populations. It cannot be otherwise when the ABS's primary engagement with remote Indigenous populations is on a short-term basis once every five years.

\section{Harnessing local knowledge more effectively}

The detailed description of the course of the census count in part of the Yolngu area of Arnhem Land (Chapter 4) highlighted the major causes of mobility in that particular region: funerals, first and foremost, and other contributory factors such as the need to visit service centres and visit kin in other communities. Although contingent and therefore unpredictable events such as the death of a particular person initiate episodes of mobility, once that mobility is in train its patterns are to some extent predictable to people with detailed knowledge of the networks of kinship and ceremonial connections in a particular region - in other words, to locals with local knowledge. The IES could make much better use of this store of knowledge than it does at the moment, by giving greater 
responsibility for the planning of the count to locals. It could not do this at the moment, because locals are not qualified to take on such a responsibility.

The CC position therefore needs substantial rethinking, in the context of continuing engagement with local organisations and regional authorities. The emphasis should be on training selected employees-Indigenous and non-Indigenous - in basic demographic methodology, and on their employment on micro-demographic projects and other surveys between censuses, as has happened at Wadeye and Tangentyere, so that, come census time, there is for each Collection District (CD) a set of people already trained for the enhanced CC role. This will decrease the burden on the CFO, who will be able to take a genuinely regional approach to their task and make better and more systematic use of the local knowledge of the CCs. For example, CCs could be alerted to watch out for patterns in the PTA data as they emerge in the field, so that crosschecking with other communities can take place at that point, rather than after the fact. They could also be instrumental in preparing access to local administrative data sets that could assist in providing vital demographic data such as dates of birth.

The enhanced CC role should be extended to responsibility for recruitment and training of the CI workforce. This should enable the training of CIs to take place in a less hurried manner-because it will not be dependent on the presence of the $\mathrm{CFO}$ - and will most likely improve recruitment and retention rates because the CCs will be local, will not have to leave the area during the count and will have received some basic training in the management of their CI workforce.

These individuals would be a permanent resource that the ABS could call on. They could be involved actively in promoting the census to their own communities, in engaging and training the CI workforce for the census and in planning the count itself. The role of the CFO would be transformed, and the current regional structure could probably be maintained. In effect, what we suggest is an enhancement of the role of the CC, who would now be a trained person with experience in other survey work for the community, and a corresponding change in the $\mathrm{CFO}$ role to that of a regional coordinator and facilitator, with specialist knowledge of census procedures. The CFOs would still provide the CCs with training to carry out the particular census tasks, but they would be training people who already had the skill set required for the job.

These recommendations, if implemented, should also result in less drawn-out counts. It seems incontrovertible that the more the period of the count is extended, the more complex the PTA problem becomes, and the more scope there is for double-counting and for missing people altogether.

All of these recommendations would also improve other aspects of the count. They would result in substantially more complete sets of data for the questions on the form that relate to factors other than just basic age, sex and usual residence. More highly trained CCs would also be able to deliver better training 
to the CIs on the purposes and meaning of the questions, resulting in improvements in the quality of the data collected.

Underpinning all these changes there should be a much better use of information technology. Databases that are updated in the field for their areas of responsibility by the CFOs and/or the CCs to show the current progress of the count - and that are accessible to all CFOs - would make the task of assessing PTA data much easier in the field, particularly where mobility is occurring across regional boundaries.

It is likely that the institutional landscape of remote Australia, particularly in the Northern Territory, will look very different in 2011. The Northern Territory government's plans for the development of regional authorities and shires is proceeding apace, and many local community organisations will cease to exist, or will be amalgamated into larger organisations with altered functions. The need for good local population data will, however, still be there. Many of the well-established organisations will survive. They will continue to deliver services and infrastructure under contract to their local shires, and increasingly they will become agencies that support and deliver economic development to their members. Unless the ABS keeps abreast of these changes it will experience considerable logistical difficulties in the field in 2011.

At one level, this reorganisation of service delivery in remote parts of the Territory will simplify the task of the ABS: there will be fewer organisations on the ground. At another level, it could increase the difficulty of compiling and updating information at the level of the community or the $\mathrm{CD}$, unless the new regional authorities have the capacity to assist the ABS in this task.

\section{The mutual benefits of continual engagement}

For their part, many community organisations - and regional authorities once they are established-would probably welcome a continuing engagement with the ABS. Good-quality demographic data at the local level would help them in their planning at many levels, yet they do not currently have the expertise, time or resources to gather these data effectively for themselves. As a result, local administrative data sets are often very inadequate, and although there is much informal knowledge about patterns of mobility and their effects, formal analyses of mobility are almost non-existent. The ABS - by involving itself creatively in training staff of regional authorities and local organisations to carry out such work - would be helping them help themselves, while simultaneously building capacity in individuals that could be utilised at census time, and also in the context of other ABS surveys.

The symbiotic relationship between the ABS and regional authorities and community organisations would have benefits for all. It would lead to a vast improvement in local administrative data sets and to a more cooperative attitude 
on the part of organisations in allowing these to be used to validate the census count. Locally based research on patterns of mobility could also contribute significantly to our understanding of population mobility in remote Australia.

\section{Keeping abreast of socio-demographic change}

Between now and 2011, there will be considerable changes in the Indigenous landscape in remote Australia, particularly in the Northern Territory, as a result of Commonwealth government policy settings. It is possible that many small outstation or homeland communities will cease to exist, owing to the withdrawal of funding for community housing and infrastructure. It has been proposed that the Community Housing and Infrastructure Program be abolished and that new initiatives to address the need for housing should '[c]ontinue the shift away from building housing on "on country" outstations and homelands and focus on building new housing where there is access to education, health, law and order and other basic services' (PricewaterhouseCooper 2007: 23). Recent changes to - and indeed the abolition of - the CDEP program, and the projected removal of the remote-area exemption for Newstart participants could also have the effect of turning many outstation dwellers into 'economic migrants', compelled to move to larger population centres in pursuit of 'real' jobs. Once again, the ABS needs to monitor these processes in the period leading up to the 2011 census, and the most efficient way to do so is to enlist the local knowledge of the staff of regional authorities and local community organisations.

\section{A new way of thinking}

These suggestions involve a new way of thinking about the engagement between the ABS and the Indigenous public, as mediated by the census. They would involve a radical change in the IES. Instead of being an intermittent strategy that manifests itself temporarily every five years, it would become a continual process of engagement. This would obviously have implications for the internal structure of the ABS, at least in the Northern Territory. It would involve the development of an Indigenous engagement unit to replace the single State Indigenous Manager. The unit's initial role would be to make an audit of regional authorities and community organisations to assess their potential as, and interest in being, sites for the training of local people as, in effect, population specialists. The unit could also be responsible for keeping the DICD for its State or Territory up to date. As noted above, given the likelihood of sweeping changes in the institutional landscape of remote Australia in the next few years - and the possibility of substantial changes in settlement patterns - this will be an important task if the ABS is to have good local knowledge in 2011. The development of training materials and local projects would necessitate creative engagement with the TAFE system and/or Charles Darwin University and other tertiary institutions around the country. Certain projects could be 
university-based research projects with the local organisations as contributing partners.

What is being advocated here is not just incremental improvements to the IES and therefore to the quality of census data on Indigenous Australians. It is a proposal for a new kind of engagement with Indigenous organisations and local government agencies that will ultimately yield high-quality micro-demographic data that will be of substantial benefit to local communities, while simultaneously contributing to the success of future censuses. It is a proposal to harness the agency of local Indigenous people more effectively, in an organisational setting, in pursuit of a strategy that better addresses the complex contingencies that the census process confronts in the field in remote Indigenous Australia.

\section{Postscript: the census and the construction of Indigenous identity}

In this book, we have largely taken the existence and the nature of the census as 'given', as a necessary part of the armoury of the modern nation-state. We have focused on ways to make the census in remote Indigenous Australia more effective, in its own terms. We have also pointed to the limitations of the census as a means of capturing and elucidating the social processes and cultural values that pattern the 'facts' of Indigenous demography. We have drawn attention to the culturally constructed nature of Indigenous responses to such questions as those on language and religion, and to the distortion of Indigenous family and household structures that occurs when Western categorisations are imposed on them (see also Morphy 2007). We have also drawn attention to the 'silences' in the data. In particular, the census is silent on significant aspects of remote Indigenous economic activity, such as income derived from art production and the contribution of subsistence activities such as hunting and gathering. This wider question of how Indigenous populations are represented in the census is discussed in most detail in Chapter 8 . It has also been addressed previously to some extent in the literature (Ellanna et al. 1988; Jonas 1992; Martin et al. 2002; Martin and Taylor 1996; Morphy 2004, 2006, 2007; Smith 1992).

In making such observations, however, we are also alluding to a literature that we have not addressed explicitly in this monograph: the work of anthropological demographers who critique the cultural assumptions underlying the construction of demographic categories (for example, Bledsoe 2002; Kertzer and Fricke 1997; Szreter et al. 2004), and who examine the role of state instruments such as the census in the construction of sub-national identities (for example, Kertzer and Arel 2002). Taken together, critiques such as these point to the essentially political nature of the census as a tool by which the state makes its citizens 'legible' and thus able to be acted on (Scott 1998). Benedict Anderson (2006: 163) calls the census - specifically in the context of colonial states - an 'institution of power'. As colonised subjects, the Indigenous people of Australia find 
themselves being categorised and made legible in terms of the assumptions of the settler state that now encapsulates them. The view of them that is constructed in this way feeds in turn into government policy settings and programs. Currently the state - through measures such as the 'National Emergency' intervention in the Northern Territory - is inserting itself ever deeper into the lives of Indigenous people in remote areas. As bodies such as the United Nations recognise (Taylor 2007a), there is an urgent need for a critique of the categories that underlie the census and also other survey tools that the state deploys to capture the demographic and socioeconomic characteristics of Indigenous Australians. 